\title{
La lucha contra la inefabilidad: el caso de Art Spiegelman
}

\author{
Raquel Crisóstomo Gálvez
}

Facultad de Ciencias de la Comunicación

Universitat Internacional de Catalunya

Raquel Crisóstomo Gálvez es doctora en Humanidades por la Universitat Pompeu Fabra. Es profesora en la Facultad de Ciencias de la Comunicación de la Universitat Internacional de Catalunya desde 2010 y jefa de los estudios de Periodismo desde 2012. Sus principales líneas de investigación son la narrativa secuencial, la narrativa visual y la serialidad televisiva. 


\title{
Resumen
}

Art Spiegelman lleva toda su vida artística luchando con como expresar lo inexpresable. E1 Horresco Referens, el horror a la referencia es uno de los ejes narrativos de su obra gráfica. En el caso de Maus (1986), el autor se enfrentó a muchos dilemas representativos: en cuanto a la capacidad explicativa del trauma paterno; los problemas que conlleva la autobiografía; pero sobre todo, la problematica de la representabilidad de la magnitud del Holocausto, tratada por primera vez en este cómic.

\begin{abstract}
Art Spiegelman has spent his entire artistic life struggling with how to express the inexpressible. The horresco referens, the horror of reference is one of the main narrative of his graphic work. In the case of Maus (1986), the author faced many representative dilemmas: how to deal with the explanatory power of parental trauma, the problems with the autobiography, but above all, the problem of representability of the magnitude of the Holocaust, first addressed in this comic.
\end{abstract}




\section{Introducción}

Art Spiegelman lleva toda su vida artística luchando con como expresar lo inexpresable. E1 Horresco Referens, el horror a la referencia es uno de los ejes narrativos de su obra gráfica. En el caso de Maus (1986), el autor se enfrentó a muchos dilemas representativos: en cuanto a la capacidad explicativa del trauma paterno; los problemas que conlleva la autobiografía; pero sobre todo, la problemática de la representabilidad de la magnitud del Holocausto, tratada por primera vez en este cómic.

Pero la historia quiso que Spiegelman no dejara nunca de lado esa inquietud representativa que le es inherente: el cartoonist vivió en primera persona la tragedia del 11/S y en In the Shadow of No Towers (2003) lidiaba otra vez con nuevos y viejos traumas particulares y con su plasmación, que ya habían nacido en 1972 con el cómic sobre el suicidio de su madre Prisoner on the Hell Planet. Spiegelman llegaría a decir que "el desastre es su musa".

Maus es un documento sobre la Shoah, la crónica de un hijo que aspira a comprender a un padre traumatizado: un viaje interior que trata de unir presente y pasado, la exploración de unas circunstancias trágicas, una reflexión sobre aquellos que sobrevivieron y aquellos que murieron ("los hundidos y los salvados", como diría Primo Levi) y un intento de superar el abismo generacional provocado por la edad y el dolor del superviviente. Así pues, el objetivo de este artículo es ver como a través de las citadas obras el autor se enfrenta a este tipo de representación en un arte tan complejo y rico como es el cómic, que imbrica grafismo y textualidad; así como también observar cómo evolucionan las respuestas que Spiegelman halla a lo largo de su trayectoria creadora.

\section{Maus, la expresión del trauma.}

Spiegelman plantea la historia de Maus como una fábula, como una narrativa que en su lectura más básica es un diálogo entre animales parlantes, concretamente entre dos ratones, un padre y un hijo, que hablan sobre las vicisitudes vividas por el padre a manos de los gatos perseguidores (nazis). Lo que hace claramente Art Spiegelman es recoger la tradición fabulística que comienza con Esopo; pasando por Jean de La Fontaine (16211695); el último cuento publicado por Franz Kafka, Josephine, die Sängerin, oder Das Volk der Mäuse (1924); o el Animal Farm de George Orwell (1945). El autor traslada los elementos esenciales de esta tradición, de estos precedentes de estos animales que hablan, a través de la incorporación de testimonios reales a su narrativa. El objetivo primero es que el lector se pueda alejar suficientemente de la experiencia del horror que representa siempre la historia de un superviviente del Holocausto, y así, acercarla a través del distanciamiento. Pero este recurso, a pesar de ayudar a tomar distancia, acaba por convertirse en algo más sofisticado. Como dice Andreas Huyssen:

The use of mice and cats is thus not simply an avantgardist distancing device in order to give the reader a fresh, critical, perhaps even 'transgressive' view of the Holocaust intended to attack the various pieties and official memorializations that have covered it discursively.2

\footnotetext{
1 “'After all, disaster is my muse'. Art Spiegelman's In the shadow of no towers". Annual Conference of the German Association of American Studies, Goettingen. University of Goettingen. Junio de 2006.

2 Huyssen, A. "Of Mice and Mimesis: Reading Spiegelman with Adorno", New German Critique, n. ${ }^{2} 81$ (2000), pp. 65-82.
} 
El problema narrativo apunta aquí al uso de la oralidad en esta obra, y a su importancia. Como muy bien comenta Michael E. Staub, esta obra, en tanto que cuento, también es narrativa oral ya que Art trabaja desde un primer momento con las cintas que grabó con su padre:

\begin{abstract}
Maus needs to be understood not only as a comic book, but also as an oral narrative, one that struggles to represent, in pictures and writing, spoken memories. As such, it is part of a larger tradition in twentieth century minority and ethnic literature: narratives that rely on the immediacy and authority of oral encounters with members of persecuted and oppressed groups in order to counter "official versions" of history that marginalize or even deny these groups' experiences and perspectives. ${ }^{3}$
\end{abstract}

La autoridad que despierta la oralidad tiene resonancias y funciones diferentes en cada grupo étnico, pero al final todas las narrativas orales elaboran diferentes opciones estratégicas para representar el recuerdo. A pesar de su condición inusual de novela gráfica, Maus es notablemente tradicional en sus estrategias documentales en cuanto a su narrativa oral. Este componente es común a diversos relatos de segunda generación, de hijos de supervivientes del Holocausto, o de experiencias de guerra, como atestigua Paula S. Fass:

Now, I have come to reclaim this other history, the history that my parents gave me in the form of memory. I am convinced that this memory is essential so that the experience of the Holocaust can be fully known and documented. Only memory can make the astounding magnitude of Holocaust destruction into real history; only memory can prevent its reduction to the incantation of a bewildering number whose dimensions are just too huge to be humanly meaningful. I hope the following demonstrates that even the memoir of a single family can reveal the richness and diversity of the people erased by the Holocaust. ${ }^{4}$

No solo Vladek elimina sus demonios a través del arte, sino también el propio Art Spiegelman, quien refiriéndose a sí mismo, explica en el prólogo de la edición española de su obra Breakdowns que:

Aunque las páginas creadas a duras penas que ese engreído reunió en Breakdowns -refiriéndose a sí mismo- se contaban entre los primeros mapas que llevaron a los cómics a ser aceptados en las librerías, bibliotecas, museos y universidades de la actualidad, él no estaba realizando un intento consciente por lograr la respetabilidad cultural. Una vez que los dibujantes underground dieron rienda suelta a sus demonios en el medio alegremente vernáculo de los cómics, pudo fijarse en la gramática de esa lengua vernácula y centrarse en sus propios demonios personales. Arte culto y popular. Palabras y dibujos. Forma y contenido. Puede que parezca árido y académico, pero -¡caray!- para mí entonces era cuestión de vida o muerte. ${ }^{5}$

\footnotetext{
${ }^{3}$ Staub, E. "The Shoah Goes on and on: Remembrance and Representation in Art Spiegelman's Maus". MELUS, n. 20 (1995), pp. 33-46.

${ }^{4}$ FAss, P. Inheriting Holocaust. A Second-Generetion Memoir. New Brunswick, Rutgers University Press, 2009, p. 4.

${ }^{5}$ Spiegelman, A. Breakdowns, Barcelona, Mondadori, 2008.
} 
Maus responde pues a la necesidad de comunicación de su trauma y de como encontró en el cómic una "gramática de esa lengua vernácula", para vehicular los propios demonios y el llamado Horresco referens. Este topos latino significa literalmente horror a la referencia y describe la imposibilidad de narración ante la percepción del horror, de aquello inefable que rodea esta circunstancia. Se trata de un lugar común bien definido porque la representación de lo horrible siempre ha sido un problema en todas las preceptivas y durante todas las épocas. Como el filósofo francés postmodernista Jean-François Lyotard observaba, el Holocausto especialmente es un ejemplo de este lugar común ya que representa un límite para la posibilidad de representación testimonial:

To have really seen with his own eyes' a gas chamber would be the condition which gives one the authority to say that it exists and to persuade the unbeliever. Yet it is still necessary to prove that the gas chamber was killing at the moment it was seen. The only acceptable proof that it was killing is that one died from it. But if one died from it one cannot testify that it is because of the gas chamber. ${ }^{6}$

Observamos como Vladek Spiegelman da testimonio a través de la obra de su hijo, que le ayuda a cerrar antiguas heridas y a expresar la angustia de la supervivencia, ya que hasta entonces ha estado inmerso en un proceso de negación, bien ilustrado por la quema de los diarios de Anya. ${ }^{7}$ Vladek pasa por el proceso catárquico que evoluciona desde la incapacidad para hablar, después de años de aparente olvido, a la verbalización a través del arte (en este caso, escribiendo / dibujando a través de la mano de su hijo Art). De hecho, "Maus is very much about the inability of art (or Art) to confront fully or represent metaphorically a monstrous past". ${ }^{8}$ Spiegelman declara que, a pesar de no tener la pretensión de legitimar el arte en el que se mueve, su obra resultó pionera y un precedente para el mundo del cómic moderno. Lo que nos interesa aquí son las palabras que utiliza en relación al lenguaje y a propósito de Maus: la necesidad de comunicación de su trauma y de como encontró en el cómic una "gramática de esa lengua vernácula", 9 para vehicular sus propios demonios.

In the Shadow of No Towers, como Maus, también es una historia de supervivencia familiar. De hecho, el mismo autor establece una continuidad biográfica en No towers, cuando hace referencia al olor característico del aire en el 11-S, en comparación al de las chimeneas de los campos: "I remember my father trying to describe what the smoke in Auschwitz smelled like [...] The closest he got was telling to me it was...'indescribable' [...] That's exactly what the air in Lower Manhattan smelled like after Sept. 11!" ${ }^{10}$ Las memorias de Spiegelman, las del recuerdo ajeno, se han convertido también en propias, tal com explica Paula S. Fass:

Although many of their memories became mine, it was always clear to me that the loss they had experienced would never be mine. Because I had not suffered, I imagined that the memo-

\footnotetext{
${ }^{6}$ Lyotard, J. “The Different, The Referent, and the Proper Name”, en Diacritics, n. 14 (1984), p. 4.

7 "Después de la muerte de Anja tuve que ordenarlo todo. Esos papeles contenían demasiados recuerdos, por ello los quemé [...]." Spiegelman, A. Maus: My Father Bleeds History Pt. 1: A Survivor's Tale. Nueva York, Penguin Books, 1989, p. 159.

8 Staub, M. Op. cit., pp. 33-46.

9 Spiegelman, A., Breakdowns, Barcelona, Mondadori, 2009.

10 Disponible on line en http://bezalel.secured.co.il/8/moller15.files/image002.jpg [Consulta: 3 de agosto de 2010].
} 
ries themselves were not really mine or rather that I had no claim to them because my memories lacked the pain that was theirs. If I had not suffered, then I had no authentic memories. It has taken me many years to recognize that not only are the memories mine but that some of the pain is mine as well. ${ }^{11}$

Al fin y al cabo Spiegelman es un creador experiencial, que materializa los traumas en sus obras:

The rubble of the World Trade Center was a historical "gift" that fell into his lap —almost literally, since he lives in Lower Manhattan - a trauma finally his own, in wich historical catastrophe is both personal and family history, as it was in Maus. ${ }^{12}$

Como vemos, ante del horror vivido, se intuye un camino: el arte, que se convierte en mágico, es un espejo transfigurador que salva, cuyo resultado es lo sublime; y la escritura se convierte en algo catárquico:

The act of telling, too, is complicated in postmodernist fashion both by Art/Artie's freqüent portrayal of the act (and difficulty) of creating the project of Maus (e.g. he draws himself at his drafting board, surrounded by mouse corpses that simultaneously represent the carnage of the Holocaust and his own guilty role as the maker and destroyer of the characters in his own work). ${ }^{13}$

E1 profesor de literatura comparada judía de la Hebrew University of Jerusalem, Sidra DeKoven Ezrahí, se refiere a la escritura después de la Shoah: "Precisely when it is most confined to the unimaginable facts of violence and horror, the creative literature that has developed is the least consistent with traditional moral and artistic conventions." ${ }^{14}$

\section{La gestión de la memoria ajena.}

Para Art Spiegelman, la creación de Maus le ayuda a ser consciente del horror vivido por sus padres, que a pesar de ser ajeno, se convierte en una experiencia propia por el hecho de formar parte de la siguiente generación a los supervivientes directos y por todas las repercusiones que esto ha comportado en su vida.

La historia que nos ocupa ilustra la problemática de la autobiografía, un género con un papel clave en el mantenimiento de la memoria. El historiador Wilhelm Dilthey (18331911) remarcaba la importancia del género autobiográfico para entender la historia; $y$ el filósofo Georges Gusdorf (1912-2000) defendía que el proceso de escritura era muy importante: la autobiografía reune pasado y presente, y comporta sobre todo el esfuerzo

${ }^{11}$ FAss, P Op. cit., p. 3.

12 Orban, K. "Trauma and visualiy: Art Spiegelman's Maus and In the Shadow of No Towers" Representations, 2007.

${ }_{13}$ Geis, D. (ed.). Considering Maus, Approaches to Art Spiegelman's "Survivor's Tale" of the Holocaust, Tuscaloosa, University of Alabama Press, 2003, p. 2.

${ }^{14}$ GeIs, D. (ed.). Op. cit., p. 3. 
de asumir el pasado para explicar el presente. Tanto el teórico Tzvetan Todorov (1939-); como el intelectual francés (hijo de un judío polaco deportado a Auschwitz) Alain Finkielkraut (1949-), escribieron que toda sociedad tiene un deber hacia su pasado, el deber de conservar la memoria de las anteriores generaciones.

Todorov utiliza el término Yiddishkeit en El hombre desplazado para referirse al conjunto de ideas, idiosincracias y sentimientos globales que acompañan a la comunidad judía alrededor del mundo. Se refiere al hecho de sentirse judío, independientemente del judaismo como a religión, tal como explica minuciosamente el experto en estudios judíos Jacob Neusner:

\begin{abstract}
Not all Jews are religious at all. Some do not believe in God. They define themselves as an ethnic group or nationality deriving from a common history and secular culture or, in the State of Israel, as a nationality - but not as a religious community sharing a way of life and a worldview. Their atheism does not change their status as part of the Jewish people viewed as a secular, social entity, a "people," an ethnic group, a nationality, even as a nation-state. ${ }^{15}$
\end{abstract}

Este sentimiento de identidad judía es una manera de seguir considerándose judíos en el mundo moderno a partir de finales del siglo XIX, a la vez que se es incrédulo, agnóstico, humanista, laico o ateo. Y este es otro de los grandes temas que se apuntan en Maus:

\begin{abstract}
Maus is, above all, the story of Spiegelman's reentry or reconversion to Judaism. Although having become a bar mitzvah, Spiegelman told one interviewer that during his mid-teens "I often thought life would be a lot easier if I were not Jewish." Yet, later he found himself unable to resist reading all he could about the Holocaust, even travelling to Auschwitz, the capacity to be addressed by the Shoah, rather than any Traditional ritual, served as Spiegelman's Jewish catalyst. This phenomenon is common in novels and short stories which view Judaism in terms of a secular value system. ${ }^{16}$
\end{abstract}

Por judeidad entendemos, pues, no sólo las ideas concebidas en el judaismo, sinó también la circunstancia del hombre judío de carne y huesos, las formas de asumir su pertenencia al judaismo. Esta condición queda reflejada en la obra de Spiegelman como un sentimiento de pérdida de esta emoción conjunta: a causa del Holocausto, de tratarse de una persona de familia judía criada en Nueva York fuera de una comundad judía, con otros referentes culturales; y sobre todo con el sentimiento de culpa como judío de la segunda generación superviviente a la Shoah, perteneciente a la generación del recuerdo ajeno. Por eso "a pivotal subject of $M y$ Father Bleeds History is Art's effort to recover a lost book, his mother's diary about her time in the camps; the search for this missing narrative becomes a working metaphor for the ultimate unrecoverability of all Holocaust experiences."'7

La memoria se plantea pues como el único lugar de acceso al descubrimiento de sí mismo, al descubrimiento del otro que hay en él, de aquel judío real anhelado en que quiere convertirse, y la escritura y la lectura como únicos medios tangibles para acceder a un pasado no conocido: "conocerla, [la judeidad] frecuentarla en los libros (únicos lugares donde

15 Neusner, J. Judaism: the Basics. New York, Routledge, 2006, p. 5.

16 Berger, A. "Bearing Witness: Second Generation Literature of the Shoah", Modern Judaism 10.1 (1990), pp. 43-63.

17 Staub, M. Op. cit., pp. 33-46. 
sigue manifestándose), es tomar medida de mi extrañeza". ${ }^{18} \mathrm{Y}$ hablamos de un "pasado no conocido" porque en la generación a la que pertenece el autor esta judeidad ya se ha perdido, y solo queda una apariencia que denuncia con constancia la Shoah, que presume de ser ostensiblemente judía, y que no obstante, su existencia precisamente se basa en la recuperación de esta judeidad desconocida, verídica pero incompleta, sin esencia, tan solo testimonio de los acontecimientos históricos, y no el alma de los pueblos:

Así que el pueblo judío ha muerto dos veces: muerto asesinado y muerto de olvido. En nuestra memoria colectiva (que no la individual) sólo hay espacio para las personas que se nos parecen, o para las piezas de museo y las curiosidades de feria [...] Así es, pues, el culto oficial de los muertos: una falsificación. Se nos describe con un torrente de lágrimas el asesinato de un pueblo senil, mientras que lo que los nazis mataron era una cultura viva, multiforme y creativa. No cabe duda de que la pura y simple indiferencia sería menos perniciosa que esa forma de conmiseración. ${ }^{19}$

E1 segundo problema que se deriva del recuerdo es el riesgo de mitificación. En la actualidad los recuerdos se han transmutado en imágenes. ${ }^{20}$ Peor todavía, son imágenes reiterativas que nos quedan en la retina después del bombardeo diario que padecemos y de las que tenemos constancia en fotografía, y que muchas veces acaban colgades en una galería de arte, quizás un lugar no demasiado propicio para el recuerdo, sino para el arte; y otras convertidas prácticamente en imagen de reverencia casi religiosa. Esta artistificación es peligrosa porque en muchas ocasiones desposee a la fotografía de su calidad de recuerdo, sin permitirse el aprenendizaje que da la reflexión sobre el objeto. Este peligro de enaltecimiento de la obra de arte es parte del remordimiento y la carga emocional que arrastra Art Spiegelman después de la publicación de su obra. Como vemos en una entrevista realizada entonces, el autor tenía problemas para responder a la pregunta de si estaba satisfecho con Maus:

Es como si me preguntara si me gusta mi nariz... Se trata de mi vida, es la historia de mi vida. Es muy difícil trabajar en Maus y va bastante despacio; a veces tengo que tomarme unas vacaciones. Es importante que no resulte melodramática. Los dibujos están al servicio de la historia. ${ }^{21}$

El proceso de distanciamiento de la obra se hace más difícil cuando es su propia vida, tal como se ha visto en capítulos anteriores, y a esto se le debe añadir que no es sólo la vida y traumas del autor los que se exponen públicamente, sino también los paternos, y los de los supervivientes y víctimas de la Shoah en general. Por lo tanto para Art Spiegelman representa un riesgo muy alto del éxito de esta obra de arte, tal como explicita mediante un ejemplo Deborah R. Geis:

Inevitably, the amazing success of Maus tooks it toll on Spiegelman, and he even satirizes the resulting frenzy in Maus II when he shows Artie, swarmed by marketers, agents and interwievers, reduced to crying infant as he is besieged by offers [...] In a 1996 cartoon entitled "Mein

\footnotetext{
18 Finkielkraut, A. Op. cit., p. 48.

19 Finkielkraut, A. Op. cit., pp. 50-51.

20 "El problema no es que la gente recuerde por medio de fotografías, sino que sólo recuerda las fotografías. E1 recordatorio por este medio eclipsa otras formas de entendimiento y de recuerdo". Sontag. Op. cit., p. 103.

${ }^{21}$ Disponible on line en http://www.imaginaria.com.ar/02/5/caceres2.htm [Consulta el 5 de mayo de 2011].
} 
Kampf" that was published in the Sunday New York Times Magazine, he draws himself being chased by a giant mouse and says, "I still prowl the murky caverns of my memory, but now I feel like there's a 5000 pound mouse breathing down my neck!.22

Spiegelman siente la culpa que caracteriza a la generación siguiente a los supervivientes, inevitablemente ligada a la memoria, y la verbaliza cuando le confiesa a su mujer, Françoise Mouly, que "de algún modo deseaba haber estado en Auschwitz con mis padres, para saber lo que habían vivido [...] sentía culpa por haber tenido una vida más fácil que la de ellos”. Ellen S. Fine, especialista en la recepción que han hecho del Holocausto los escritores judíos hijos de superviventes, escribe sobre Spiegelman:

\begin{abstract}
That those who attempt to reconstruct their family's memories, as Spiegelman tries to do in his narrative, are often plagued by guilt and concerns about a right to use the Holocaust as a subject. They are haunted by the world that has vanished; a large gap exists in their history, and they desire to bridge this gap. However, they feel frustrated by the impotence of incomprehension; the past eludes and excludes them. ${ }^{23}$
\end{abstract}

Esta segunda generación crea un deber de militancia de la memoria de los que sufrieron los campos, sienten que tienen una responsabilidad hacias ellos:

\begin{abstract}
As we see in Maus, when these narratives are retold and mediated by the second-generation tellers whose own testimony is caught up in both the "responsibility" they feel in telling these stories and their own inability to do so. [...] Second-generation Holocaust writers have frequently shown the problematics of representation within their work as part of what they also see as an ethical response to the past [...] Indeed, one striking characteristic of secondgeneration/postmoden Holocaust literature is its resistance to catharsis. [...] This is why the mode of traditional tragedy ill suits literature of the Holocaust: the victims (as we see clearly in the case of Vladek) did not "choose" their suffering, nor were they ennobled by it. ${ }^{24}$
\end{abstract}

Esta generación de posguerra, después de todo, no puede físicamente rememorar el Holocausto como realmente tuvo lugar, porque no lo vivieron. Todo lo que recuerdan, todo lo que saben, es lo que las víctimas han escrito en sus diarios, lo que los supervivientes recordaban en sus memorias. No retenían sucesos actuales, pero sí las incontables novelas, historias y poemas sobre la Shoah que habían leído u oído durante años. Nacidos después del Holocausto, en la época de su memoria, esta generación raramente intenta representar los hechos fuera de las formas a través de las que ellos han recibido la experiencia. En vez de retratar los hechos del Holocausto, escriben, dibujan y hablan sobre su transmisión en libros, películas, fotografías e historias de sus padres. En vez de intentar recordar los hechos, sobre todo reclaman su relación con la memoria de los hechos. "What happens to the memory of history when it ceases to be testimony?", se preguntaba Alice Kaplan. ${ }^{25}$ El experto en estudios judaicos James E.Young quiere responder a esta pregunta:

\footnotetext{
22 Geis, D. (ed.). Op. cit. p. 6.

${ }^{23}$ Fine, E. “The Absent Memory: the act of writing in Post-Holocaust French Literature”, en Writing and the Holocaust, Berel Lang (ed.), New York, Holmes and Meier, 1988, p. 43.

${ }^{24}$ Geis, D. (ed.) Op. cit., p. 4.

25 Kaplan, A. “Theweleit and Spiegelman: Of Mice and Men”, en Kruger, B. y Marian, P. (eds.). Remaking History. Seattle, Bay Press, 1989, p.160.
} 
It becomes memory of the witness's memory, a vicarious past. What distinguishes many of these artists from their parents' generation of survivors is their single-minded knack for representing just this sense of vicariousness, for measuring the distance between history-as-ithappened and their own postmemory of it. ${ }^{26}$

La importancia de este recuerdo indirecto, en definitiva del nazismo hoy en día, sugiere la crisis profetizada parcialmente por Susan Sontag en su ensayo de 1975, Fascinating Fascism. ${ }^{27}$ De hecho, ya se había apuntado anteriormente la presencia de la crítica en Maus a la comercialización de las memorias del Holocausto en el mundo moderno y post-moderno.

\section{$\underline{\text { Hacer cómics después de Mauschwitz: la no-muerte representacional }}$}

En el 2004, Spiegelman publicó In the Shadow of no Towers, donde ofrecía su particular visión del 11 de septiembre de 2001. El paisaje dantesco y el desconcierto generalizado generaron en él, de nuevo, sentimientos encontrados. Él mismo decía que

superar esa nube tóxica que un instante antes era la torre norte del World Trade Center me hizo percibir íntimamente la inflexión en la cual la Historia Mundial y la Historia Personal entran en colisión. Ese punto de intersección respecto del cual mis padres, supervivientes de Auschwitz, me habían puesto en alerta enseñándome a tener siempre las maletas listas. ${ }^{28}$

A través de estas palabras, Spiegelman apunta cómo la experiencia paterna, cómo su condición de hijo de superviventes ha influido de forma decisiva no sólo en su vida, sino también en su obra, ambas imbricadas sin remedio. In the Shadow of No Towers, es por tanto, al igual que Maus, una historia de supervivencia familiar. Las memorias de Spiegelman, el recuerdo ajeno de segunda generación, han acabado siendo también suyas, propias. Al fin y al cabo, Spiegelman es un creador experiencial, que materializa sus traumas en sus obras: Los escombros del World Trade Center fueron un "regalo" histórico que le cayeron del cielo - casi literalmente, ya que Spiegelman vive en la parte baja de Manhattan-; finalmente su propio trauma, donde la catástrofe histórica es tanto personal como familiar, como ya lo fue en Maus. ${ }^{29}$ Ante el horror vivido se intuye el camino del arte, que es casi un espejo transfigurador que salva, algo catárquico. En palabras del propio Spiegelman: "Decidí que mis cómics eran la mayor terapia posible: el bote de tinta antes que el de pastillas o la visita al psicoterapeuta". ${ }^{30}$

La continuidad entre ambas obras es clara, por ejemplo, en que Spiegelman continúa usando al ratón para autorepresentarse en muchas ocasiones. Pero como él mismo ha

\footnotetext{
${ }^{26}$ Young, J. “The Holocaust as Vicarious Past: Art Spiegelman's "Maus” and the Afterimages of History”, en Critical Inquiry, n. 24 (1998), pp. 666-699.

27 Sontag, S. "Fascinating Fascism”, en New York Review of Books (1975).

28 Costa, F. "Diario impresionista en cámara lenta sobre el 11-S. Entrevista con Art Spiegelman", en Revista N, n. 107 (2005).

29 "The rubble of the World Trade Center was a historical "gift" that fell into his lap -almost literally, since he lives in Lower Manhattan- a trauma finally his own, in wich historical catastrophe is both personal and family history, as it was in Maus". Orban, K. "Trauma and visualiy: Art Spiegelman's Maus and In the Shadow of No Towers" en Representations (2007).

30 Manzano, E. “El éxito de Maus me supuso una depresión”, en La Vanguardia (1991).
} 
comentado en más de una ocasión: "Las cuestiones representacionales siempre me dejan descolocado". ${ }^{31}$ Le acompañan diversos personajes de los primeros grandes cómics como el Yellow Kid (R.F. Outcault, 1895) o el ratón Ignatz de Krazy Kat (George Herriman, 1913) entre muchos otros. El autor mimetiza estos clásicos del mundo del cómic, mezclándolos con otros recursos estilísticos y artísticos, para dar a entender su estado mental fragmentado después de los atentados y su repercusión mediática. Spiegelman está abrumado por la cuestión representacional y en ocasiones, secuestrado creativamente por la figura del "maus". De hecho en 2002 el autor se reconocía "incapaz [...] de afrontar una obra de enjundia porque la sombra de los ratones de 'Maus' es larga y pesada”. ${ }^{32}$

De hecho, la afirmación de que el desastre es su musa no podría ser más acertada: la primera obra de Spiegelman interesante, Prisoner in planet Hell, habla sobre el suicidio materno; Maus habla sobre su relación conflictiva con un padre que además es superviviente de los campos; y No towers trata del impacto vivido como testimonio del 11S.

Las estrategias narrativas de Spiegelman para lidiar con la representación de lo inefable son arriesgadas. La principal, la más visible, y la que nos ocupa, es la decisión de utilizar animales antropomorfos, en una metáfora continuada que hace de los judíos ratones y de los alemanes gatos. Menos presentes, los polacos son cerdos, posiblemente no por racismo, sino por asociación con la exportación de jamón polaco; los norteamericanos serán perros, en la acepción de fidelidad que los caracteriza, los franceses ranas, probablemente por el uso anglo-americano de la palabra frogs para referirse a los franceses, y los suecos, renos. En este punto, la decisión de Spiegelman remite a una doble herencia.

Por un lado, la tradición de los funny animals del mundo de la historieta y del cine de animación: no es ninguna casualidad que el niño de la primera versión de Maus de 1972 se llame Mickey, tal como explica en el primer capítulo de Metamaus. ${ }^{33}$ Por otra parte, Spiegelman se apropia del tópico antisemita de la representación de los judíos como ratas, con mucha difusión en discursos y caricaturas en diarios y publicaciones nazis, como el Der Stürmer, por ejemplo. En términos generales, Spiegelman retoma la división que hacían los nazis de los humanos en especies, argumento que les "permitía" exterminar (en lugar de matar) a las ratas judías. Por eso el mismo Spiegelman ha dicho en más de una ocasión que Maus fue creado en colaboración con Hitler. ${ }^{34}$

En cualquier caso, el uso de animales humanizados habla de un problema estético y moral que ronda a los artistas que se han enfrentado al Holocausto y plantea preguntas que ya se han venido formulando anteriormente: ¿cómo representar un horror que supera las definiciones mismas de aquello humano? ¿Tiene derecho un artista a hacer una ficción o a estilizar este horror? ¿No sería mejor dejar hablar a los documentos y a los testimonios de los supervivientes, sin las frivolidades del arte? Y más grave todavía: ¿ُun artista tiene derecho a obtener un beneficio económico de este horror?

\footnotetext{
31 De Wildt, L. “Entwining the National and Personal: Art Spiegelman's Post-9/11 Shapeshifting”, disponible on line en http://www.inter-disciplinary.net/probing-the-boundaries/wp-content/uploads/2013/09/ SHAPE1-paper LAWJ-de-Wildt.pdf [consultado el 17 de febrero de 2014].

32 Llopart, S. “Art Spiegelman's: “En 'Maus' los judíos son ratones porque así los veía el nazismo”, en $L a$ Vanguardia, 2002.

33 Spiegelman, A., Metamaus, New York, Pantheon, 2011.

34 Disponible on line en http://www.nybooks.com/blogs/nyrblog/2011/oct/20/why-mice/ [Consulta: 17 de febrero de 2014]
} 
Aunque Maus fue recibido con elogios prácticamente unánimes, entre la crítica más conservadora suscitó algunas reticencias por dos aspectos en concreto: el primero, el hecho de que fuera un cómic que trataba el tema del Holocausto, y en segundo lugar que además estuviera protagonizado por animales. Por ejemplo, el guionista norteamericano pionero del cómic alternativo, Harvey Pekar, cuestionó en particular el uso de esta metáfora en cuanto a la representación de los polacos como cerdos, ${ }^{35}$ lo que implica una pérdida de control sobre los sentidos de la metáfora, ya que aunque filtrada y resignificada, aún conserva parte de su capacidad ofensiva original.

El propio Spiegelman plantea de forma abierta el problema de la representación animalizada en varias ocasiones a su obra. En un momento de Maus, por ejemplo, un Art que se empequeñece cada vez en su silla, es cuestionado por un periodista con máscara de ratón judío que le pregunta sobre qué animal utilizaría para representar a los judíos israelíes. Tal y como está formulada la pregunta, de entrada se entiende que se descarta la misma representación que se utiliza por los judíos retratados por Spiegelman, cuestión que también se intuye por el hecho de que utilice una máscara de ratón, como si este personaje fuera judío, pero sin serlo verdaderamente. En esta escena, claramente asistimos a la representación de la presión que ejerce el lobby judio en Estados Unidos, que no se puede mencionar sin ser tildado de antisemita.

Pero el riesgo del uso de la metáfora del ratón es elevado, teniendo en cuenta como han evolucionado los acontecimientos históricos relacionados con el contexto judío desde la finalización de la Segunda Guerra Mundial. Spiegelman ya empezaba a mostrar en su obra su preocupación por el tema, pero en una entrevista posterior realizada en 2002, el autor añade:

—Era inevitable que se le pidiera su punto de vista sobre el conflicto árabe-israelí.

- Es curioso, cuando en Nueva York me preguntan me parece que ejerzo de portavoz de $\mathrm{Ha}$ mas. Pero aquí en Europa me acabo sintiendo como un sionista irreductible [...] se ha llegado a un punto en que todos se equivocan. ${ }^{36}$

Spiegelman es extremadamente consciente de estos y otros problemas que derivan de la representación artística. El genocidio, la desaparición masiva de seres humanos, llevan a enfrentarse con la imposibilidad de una narración neutra, un modo transparente de representación: la decisión de utilizar animales y el registro gráfico elegido funcionan a partir de esta comprobación. El dibujo extremadamente sencillo, a veces bruto de Maus, se encuentra lejos de la expresividad de los Funny Animals de 1972, ${ }^{37}$ tanto como del expresionismo que es usado en Prisoner in Hell Planet.

Al mismo tiempo, la relación del libro con lo real es muy compleja: el relato se ofrece como un testimonio o una autobiografía a dos voces (ofreciendo al lector un pacto de verdad); incluye fotografías (del padre, de su hermano muerto Richier), y el personaje de Art aparece en ocasiones dibujado como un humano con máscara de ratón. Es una ten-

\footnotetext{
35 Bolmafner, S. "Art for Art's Sake: Spiegelman Speaks on RAW's Past, Present and Future”, en The Comics Journal, 145, 1991.

36 Llopart, S. “Art Spiegelman: “En 'Maus' los judíos son ratones porque así los veía el nazismo”, en La Vanguardia, 2002.

37 Las primeras muestras de Maus aparecieron por primera vez en tres páginas publicadas en 1972 en un magazine de cartoons de animales antropomórficos, Funny Animals, un cómic underground editado por Apex Novelties, bajo el título Rat.
} 
sión con la que Spiegelman trabajó: dibuja una historieta con ratones, pero como hemos visto, a la vez pide al The New York Times que Maus II esté en la columna de "no ficción" en su lista de Best Sellers. Por la misma razón, por la renuncia a toda inocencia narrativa, el libro no puede presentar una historia lineal, ya que se multiplican los tiempos, los niveles de ficción: habla Vladek de su experiencia en Auschwitz; habla Art del que Vladek le explicó; habla del Art humano / autor de lo que significó hacer el libro que hemos visto hacer al Art ratón / personaje.

La experiencia del horror no puede enfrentarse sin poner en crisis los propios instrumentos de la narración. Hay dos momentos notables en relación con estos problemas: el segundo capítulo de Maus II, Art le pregunta a su padre por una orquesta que, según la documentación, tocaba en el campo mientras los prisioneros marchaban. La viñeta anterior ha mostrado esta orquesta. Pero Vladek nunca la vio, y al siguiente dibujo sólo muestra los prisioneros marchando. En una primera mirada, el dibujo parece adaptarse a la corrección que Vladek hace, pero sobre las cabezas de los prisioneros pueden verse partes de una batuta y de un contrabajo: el dibujo no termina de adaptarse al testigo ni a la documentación. En otra escena, una de las más duras del libro, se muestra a un soldado alemán estampando la cabeza de un niño judío contra una pared. ${ }^{38}$ El propio Spiegelman ha comentado sus dudas al respecto: no la podía dejar fuera de la narración, pero no encontraba la manera de representarla. Así que tomó algunas decisiones: encuadrar de manera que no se vea si son animales o personas; mostrar la mancha de sangre sólo una vez, y cubrir la mancha de la segunda viñeta con el globo de Vladek, que dice: "es algo que no vi con mis propios ojos".

E1 problema ético que se deriva de la representación del Holocausto quizás tampoco tenga solución: ¿tiene derecho un artista a ganar dinero con el horror? Spiegelman ha negado de manera sistemática a producir derivados de su libro en películas y obras teatrales. Todos estos problemas aparecen en el libro, que abre el capítulo 2 de Maus II con la imagen que ya hemos visto del autor, sobre una pila de cadáveres, comentando el éxito de Maus I y recibiendo con creciente horror, propuestas para filmar películas, contestar entrevistas y aprobar merchandising. De hecho, la solapa del libro ilustra a Spiegelman con su máscara de ratón enfrentándose al problema de la representación de los campos que como vemos por la ventana, son una realidad, con un fajín de cigarrillos "Crema" sobre el mostrador de dibujo: un pequeño gesto de humor negro que asocia el humo del tabaco con el de los crematorios y que habla también de la inevitable tensión entre el Holocausto y la industria cultural que lo comercializa. Vladek termina irónicamente su cuento, diciendo: "No necesito decirte más. Fuimos muy felices, y vivimos felices, por siempre", a pesar de que Anja finalmente se hubiera suicidado.

${ }^{38}$ Maus I,1989, Op. cit., cap. 5. 


\section{Bibiliografía}

Berger, A. "Bearing Witness: Second Generation Literature of the Shoah", en Modern Judaism, n. ${ }^{\circ} 10$ (1990), pp. 43-63.

Bolhafner, S. “Art for Art's Sake: Spiegelman Speaks on RAW's Past, Present and Future”, en The Comics Journal, n. ${ }^{o} 145$ (1991).

Costa, F. "Diario impresionista en cámara lenta sobre el 11-S. Entrevista con Art Spiegelman", en Revista N, n.o 107 (2005).

De Wildt, L. "Entwining the National and Personal: Art Spiegelman's Post-9/11 Shapeshifting", disponible on line en http://www.inter-disciplinary.net/probing-the-boundaries/wpcontent/uploads/2013/09/SHAPE1-paper LAW]-de-Wildt.pdf [consultado el 17 de febrero de 2014].

FAss, P. Inheriting Holocaust. A Second-Generetion Memoir. New Brunswick, Rutgers University Press, 2009.

FInE, E. “The Absent Memory: the act of writing in Post-Holocaust French Literature”, en Writing and the Holocaust, New York, Holmes and Meier, 1988, p. 43.

Geis, D. (ed.). Considering Maus, Approaches to Art Spiegelman's "Survivor's Tale" of the Holocaust. Tuscaloosa, University of Alabama Press, 2003.

Huyssen, A. "Of Mice and Mimesis: Reading Spiegelman with Adorno",en New German Critique, n. ${ }^{\circ} 81$ (2000), pp. 65-82.

Kaplan, A. "Theweleit and Spiegelman: Of Mice and Men," en Remaking History, en Kruger, B. y Marian, P. (eds.). Remaking History. Seattle, Bay Press, 1989, p.160.

Llopart, S. “Art Spiegelman's: “En 'Maus' los judíos son ratones porque así los veía el nazismo”, en La Vanguardia (2002).

Lyotard, J. “The Different, The Referent, and the Proper Name”, en Diacritics, n. ${ }^{\circ 14}$ (1984).

Manzano, E. “El éxito de Maus me supuso una depresión”, en La Vanguardia (1991).

Neusner, J. Judaism: the Basics. New York, Routledge, 2006, p. 5.

Orbán, K. "Trauma and visualiy: Art Spiegelman's Maus and In the Shadow of No Towers", en Representations, 2007.

SontaG, S. "Fascinating Fascism", en New York Review of Books (1975).

Spiegelman, A. Breakdowns. Barcelona, Mondadori, 2009.

-Metamaus. New York, Pantheon, 2011.

Staub, M. “The Shoah Goes on and on: Remembrance and Representation in Art Spiegelman's Maus”, en MELUS, n. ${ }^{\circ} 20$ (1995), pp. 33-46.

Young, J. "The Holocaust as Vicarious Past: Art Spiegelman's "Maus" and the Afterimages of History”, en Critical Inquiry, n. ${ }^{\circ} 24$ (1998), p. 666-699. 